TPM were not explained by sedation. Mead blood levels by the 4-week test period were within clinical therapeutic ranges: TPM $(11 \mathrm{mcg} / \mathrm{mL})$; LTG (8.1); and GBP (9.6). (Martin R, Kuzniecky R, Ho S et al. Cognitive effects of topiramate, gabapentin, and lamotrigine in healthy young adults. Neurology Jan 1999;52:321327). (Reprints: Dr Roy C Martin, UAB Epilepsy Center, Department of Neurology, University of Alabama at Birmingham, 312 CIRC, 1719 6th Avenue South, Birmingham, AL 35294).

COMMENT. The adverse effects on cognitive functioning caused by topiramate in healthy young adults have also been observed in patients treated for epilepsy. The potential long-term effects beyond one month were not addressed. Early-onset side effects may subside and may be less evident when the drug is introduced more slowly.

\title{
RENAL TUBULAR DYSFUNCTION WITH VALPROATE AND CBZ
}

Renal tubular function in epileptic children receiving antiepileptic drugs was evaluated by measurement of lysosomal enzymes at Istanbul University, Turkey. N-acetyl-B-glucosaminidase and B-galactosidase were determined before and 8 months after administration of valproate in 14 children, and carbamazepine in 17, and also in 25 healthy untreated controls. Increased enzyme activities were found in patients treated with AEDs, and valproate-treated patients were affected more frequently than the carbamazepine group (50\% cf $18 \%$, respectively). (Yuksel A, Cengiz M, Seven M, Cengiz S, Cenani A. N-acetyl-B-glucosaminidase and B-galactosidase activity in children receiving antiepileptic drugs. Pediatr Neurol Jan 1999;20:24-26). (Respond: Dr Adnan Yuksel, Akdeniz Caddesi No 85 Ki, Fatih, Istanbul, Turkey).

COMMENT. Children treated with AEDs and especially valproate in large doses for extended periods may develop renal tubular dysfunction. In addition to tests of liver function, valproate-treated patients should receive urinary function tests in certain circumstances.

Valproate-induced hyponatremia is reported in an adult with HenochSchonlein nephritis who was treated with $2000 \mathrm{mg}$ /day of VPA for idiopathic epilepsy. Water loading tests at different dosages of sodium valproate showed reduced water excretion that was dose-dependent. Inappropriate secretion of antidiuretic hormone was the proposed mechanism. (Branten AJW, Wetzels JFM, Weber AM, Koene RAP. Ann Neurol February 1999;43:265-267). Having regard to the renal tubular dysfunction reported above, renal insufficiency may be an alternative explanation.

\section{CARBAMAZEPINE AND METHYLPHENIDATE LEVELS IN ADHD}

A carbamazepine (CBZ)-induced lowering of methylphenidate (MPH) serum levels in a 13-year-old female treated for ADHD and aggressive behavior, is reported from the Eastern Pennsylvania Psychiatric Institute, Philadelphia. ADHD symptoms that had responded to MPH became worse when CBZ was introduced and the dose increased to $800 \mathrm{mg} /$ day (serum level $8.9 \mathrm{mcg} / \mathrm{mL}$ ). Peak morning serum levels of MPH and ritalinic acid were $5.3 \mathrm{ng} / \mathrm{mL}$ on $20 \mathrm{mg} \mathrm{MPH} 3$ times a day (standard range of MPH level is $5-20 \mathrm{ng} / \mathrm{mL}$ ). After 6 weeks on CBZ, the MPH levels decreased to 4.2, and later to 2.4, when the dose of CBZ was increased to 1000 $\mathrm{mg} / \mathrm{day}$. ADHD symptoms worsened despite an increase in MPH dose to $35 \mathrm{mg} 3 \mathrm{x}$ daily. The beneficial effects of MPH were regained only at doses of $60 \mathrm{mg} 3 \mathrm{x}$ daily. (Schaller JL, Behar D. Carbamazepine and methylphenidate in ADHD. I Am Acad 